\title{
Examination of the Structural Quality of InAsSbBi Epilayers using Cross Section Transmission Electron Microscopy
}

Rajeev R. Kosireddy ${ }^{1}$, Stephen T. Schaefer ${ }^{2}$, Arvind J. Shalindar ${ }^{2}$, Preston T. Webster ${ }^{2,3}$, and Shane R. Johnson ${ }^{2}$

${ }^{1 .}$ Center for Photonics Innovation \& Engineering of Matter, Transport, and Energy, Arizona State University, Tempe, AZ.

2. Center for Photonics Innovation \& Electrical, Computer, and Energy Engineering, Arizona State University, Tempe, AZ.

3. Air Force Research Laboratory, Space Vehicles Directorate RVSWS, Kirtland Air Force Base, Albuquerque, NM.

Efficient infrared detection and emission is desired for numerous applications, including navigation, night vision, communications, imaging, spectroscopy, and launch detection. Incorporation of bismuth in InAs alloys results in larger bandgap reduction per unit strain than antimony and provides an efficient means of tuning the bandgap while limiting the level of biaxial strain that can introduce defects that reduce optical quality [1]. Pseudomorphic InAsSbBi grown on GaSb is of interest because it permits the designer to independently adjust bandgap and strain by varying the group- $\mathrm{V}$ mole fractions as well as providing improved hole confinement over InAsSb alone. This study describes the TEM characterization of $210 \mathrm{~nm}$ thick, pseudomorphic InAsSbBi layers grown under various V/III flux ratios and temperatures ranging from $280^{\circ} \mathrm{C}$ to $430^{\circ} \mathrm{C}$. The changes in microstructure that result from adjusting the growth conditions are reported. Cross sectional TEM samples are prepared for observation along the $<110>$ projection using standard mechanical polishing and dimple grinding, followed by argon-ion-milling (maximum beam energy $2.5 \mathrm{keV}$ ) with liquid-nitrogen cooling to reduce ion-beam damage. The electron microscopy was performed using a FEI CM-200 high-resolution electron microscope with an accelerating voltage of $200 \mathrm{kV}$.

The sample set examined consists of InAsSbBi layers grown at 1) $280{ }^{\circ} \mathrm{C}$ with $\mathrm{Bi} / \mathrm{In}$ flux ratio $0.065,2$ ) $400{ }^{\circ} \mathrm{C}$ with $\mathrm{Bi} / \mathrm{In}$ flux ratio 0.050 , and 3) $430^{\circ} \mathrm{C}$ with $\mathrm{Bi} / \mathrm{In}$ flux ratio 0.100 . The sample structure crosssection is inset in Figure 1. The structural quality of growths 1 and 2 is examined using high resolution electron microscopy at low magnification (see Figures 1 and 2). The material is observed to be defect free over large lateral distances. The observation of contrast modulation in Figure 2 indicates the presence of composition inhomogeneity in InAsSbBi grown at the higher growth temperature. The upper interfaces are imaged using high resolution electron microscopy and shown in Figures 3 and 4. The interfaces are observed to be smooth and coherent with no misfit dislocations. The high quality interfaces are confirmed by the presence of Pendellösung fringes in X-ray diffraction measurements over large angular ranges (see Figure 6). For growth 3 at the highest temperature and highest $\mathrm{Bi}$ flux, the surface morphology significantly changes via the formation of surface droplets, as observed in the electron micrograph shown in Figure 5 [2].

References:

[1] P. T. Webster et al, Appl. Phys. Lett. 111 (2017), 082104.

[2] The authors gratefully acknowledge financial support through the National Science Foundation (NSF) award DMR-1410393 and the Air Force Office for Scientific Research (AFOSR) STTR Phase II grant FA9550-16-C-0021, as well as the use of facilities in the LeRoy Eyring Center for Solid State Science at Arizona State University. 


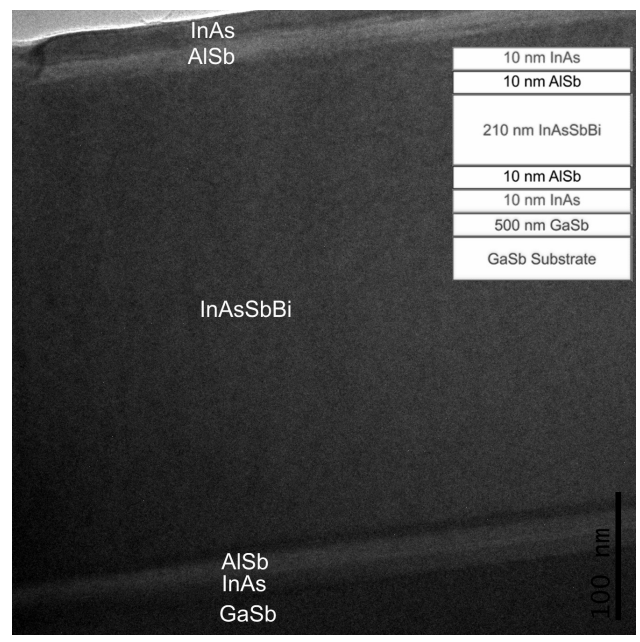

Figure 1. High resolution electron micrograph from sample grown at $280^{\circ} \mathrm{C}$; cross section inset.

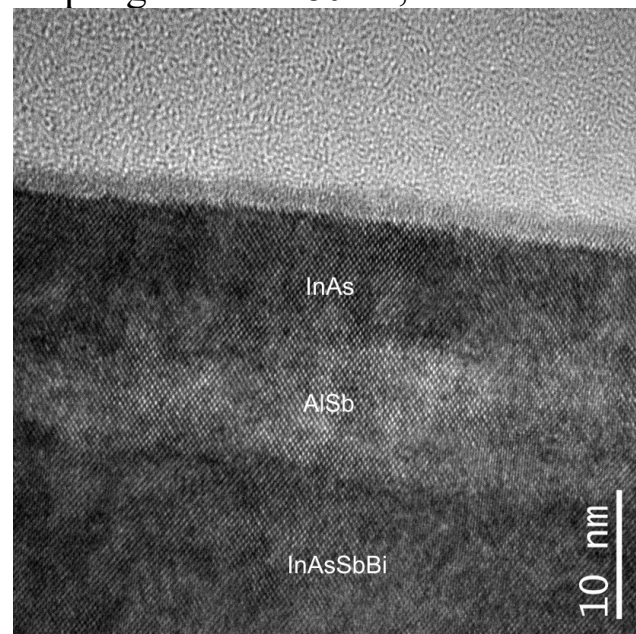

Figure 3. High resolution electron micrograph from top interface of sample grown at $280^{\circ} \mathrm{C}$.

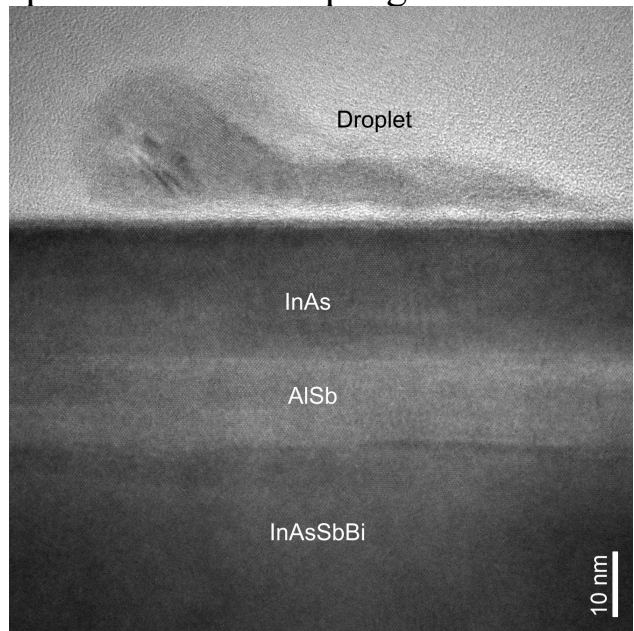

Figure 5. High resolution electron micrograph from sample grown at $430{ }^{\circ} \mathrm{C}$ showing a surface droplet.

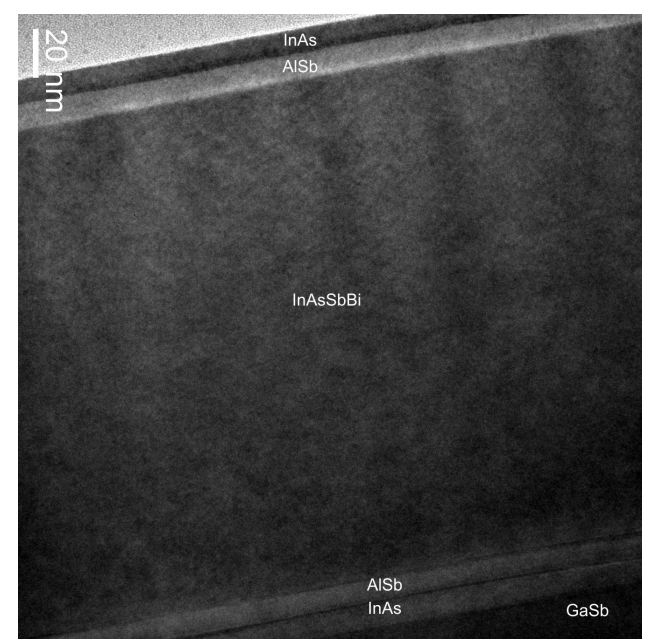

Figure 2. High resolution electron micrograph from sample grown at $400{ }^{\circ} \mathrm{C}$.

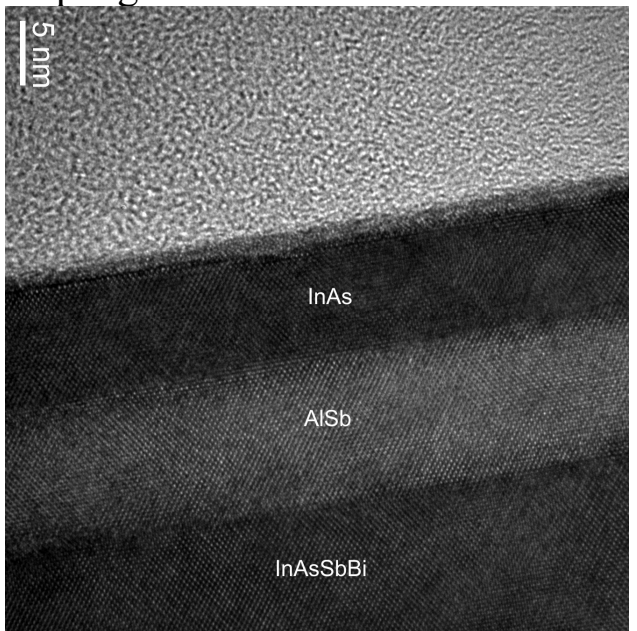

Figure 4. High resolution electron micrograph from top interface of sample grown at $400{ }^{\circ} \mathrm{C}$.

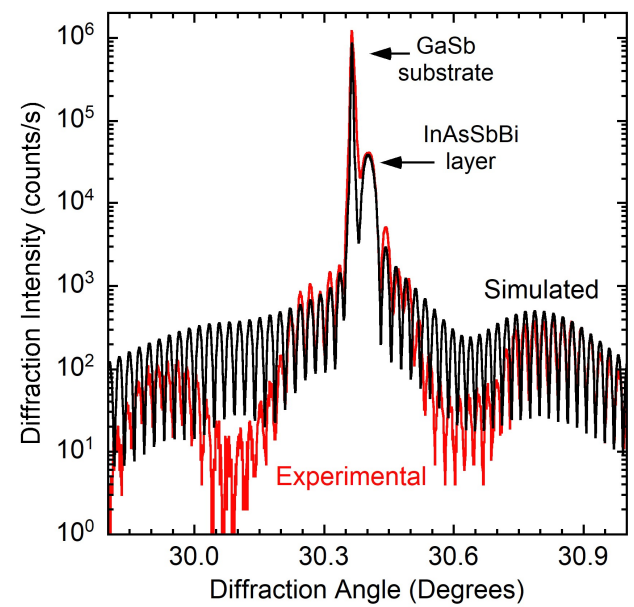

Figure 6. X-ray diffraction pattern from sample grown at $280{ }^{\circ} \mathrm{C}$. 